\title{
Developing a mathematical model to optimize long - term quarrying planing for limestone quarries producing cement in Vietnam
}

\author{
Bao Dinh Tran ${ }^{1,}{ }^{*}$, Trong Dinh Vu ${ }^{2}$, Viet Van Pham ${ }^{1}$, Tuan Anh Nguyen ${ }^{1}$, An Dinh \\ Nguyen ${ }^{1}$, Giang Huong Thi Le ${ }^{3}$ \\ ${ }^{1}$ Department of Surface Mining, Mining Faculty, Hanoi University of Mining and Geology, Vietnam \\ 2 TU Bergakademie Freiberg, 09599 Freiberg, Germany \\ ${ }^{3}$ Faculty of General Education, Hanoi University of Mining and Geology, Hanoi, Vietnam
}

\begin{abstract}
ARTICLE INFO
ABSTRACT

Article history:

Received $08^{\text {th }}$ Sept. 2020

Revised 29th Sept. 2020

Accepted $10^{\text {th }}$ Oct. 2020

Keywords:

Limestone quarry,

Long term planning,

Mathematical model,

Raw material,

Vietnam.

Mathematical model researches in optimizing long - term quarrying planning for limestone quarries supplying to the cememt factories have not been popular in Vietnam. The paper shows a mathematical model based on Mixed Integer Linear Programming as well as effective method to cope with long - term quarrying planning for the quarries. Techniques grouping block cells into a mining room and decision variable elimination techniques was employed to reduce the size of the problem. This enable to form an optimal method with proper time. The model and the algorithm are an effective tool to conduct a long - term planning for the quarries, enabling to supply the quatity and quality enough of raw materials to the factory. The model was demonstrated and practically evaluated when being applied and compared with one of the popularly commercial sofwares in mine schedule, GEOVIA Mines.
\end{abstract}

Copyright (C) 2020 Hanoi University of Mining and Geology. All rights reserved.
${ }^{*}$ Corresponding author

E - mail: trandinhbao@humg.edu.vn

DOI: 10.46326/JMES.KTLT2020.05 


\title{
Tạp chí Khoa học Kỹ thuật Mỏ - Địa chất
}

Trang điện tử: http://tapchi.humg.edu.vn

\section{Phát triển mô hình toán lập kế hoạch khai thác dài hạn tối ưu cho các mỏ đá vôi xi măng ở Việt Nam}

\author{
Trần Đình Bão ${ }^{1,}{ }^{*}$, Vũ Đình Trọng ${ }^{2}$, Phạm Văn Việt ${ }^{1}$, Nguyễn Anh Tuấn ${ }^{1}$, Nguyễn \\ Đình An ${ }^{1}$, Lê Thị Hương Giang ${ }^{3}$ \\ ${ }^{1}$ Bộ môn Khai thác lộ thiên, Khoa Mỏ, Trường Đại học Mỏ - Địa chất, Việt Nam \\ 2 Viện Mỏ và Kỹ thuật dân dụng, Trường Đại học kỹ thuật Bergakademie Freiberg, CHLB Đức \\ ${ }^{3}$ Khoa khoa học co bản, Trường Đại học Mỏ - Địa chất, Việt Nam
}

\begin{tabular}{|c|c|}
\hline THÔNG TIN BÀI BÁO & TÓM TẮT \\
\hline $\begin{array}{l}\text { Quá trình: } \\
\text { Nhận bài 08/9/2020 } \\
\text { Sưa xong 29/9/2020 } \\
\text { Chấp nhận đăng 10/10/2020 }\end{array}$ & 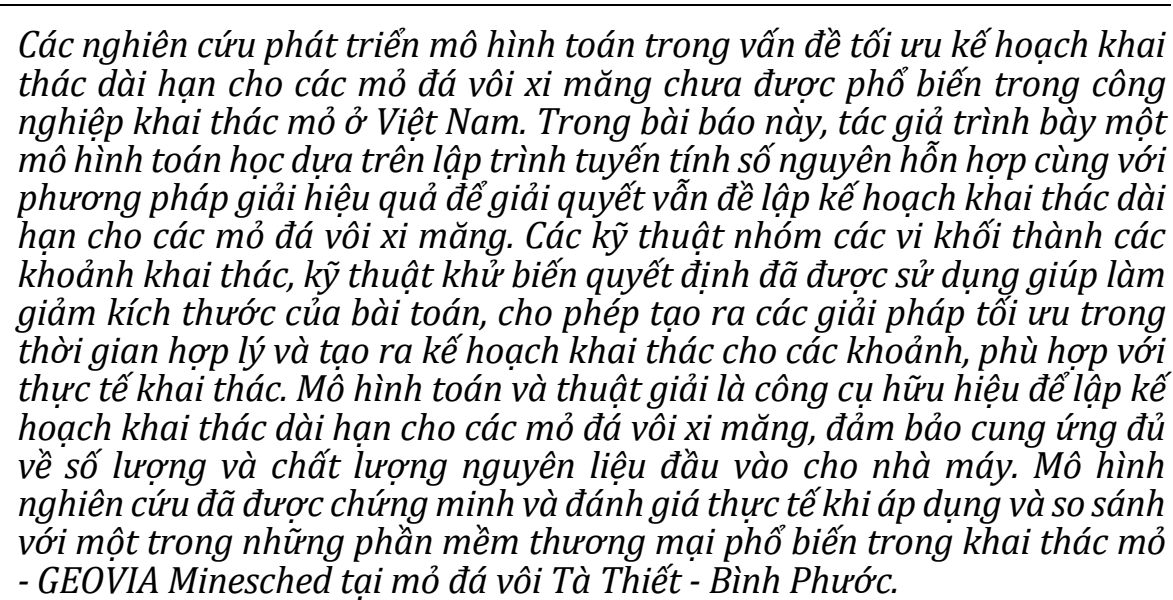 \\
\hline
\end{tabular}

(C) 2020 Trường Đại học Mỏ - Địa chất. Tất cả các quyền được bảo đảm.

\section{Mở đầu}

Để sản xuất xi măng, điều quan trọng là tạo ra hỗn hợp nguyên liệu thô có các thành phần hóa học nằm trong giới hạn xác định theo công nghệ sản xuất xi măng. Đá vôi là nguyên liệu chính để sản xuất xi măng vì thành phần khoáng hóa của đá

\footnotetext{
*Tác giả liên hệ

E- mail: trandinhbao@humg.edu.vn

DOI: $10.46326 / J M E S . K T L T 2020.05$
}

vôi thỏa mãn về chất lượng và số lượng các oxit như Cao, $\mathrm{SiO}_{2}, \mathrm{Al}_{2} \mathrm{O}_{3}, \mathrm{Fe}_{2} \mathrm{O}_{3}$. Thông thường, đá vôi sau khi được khai thác từ mỏ sẽ được trộn với nhau hoặc trộn với các chất phụ gia (tro bay, quặng sắt,...). Một dự án khai thác mỏ đá vôi xi măng (mỏ đá vôi cung cấp nguyên liệu thô cho các nhà máy xi măng) được cho là thành công khi mà đảm bảo cung cấp đầy đủ hỗn hợp nguyên liệu thô cho nhà máy sản xuất xi măng một cách liên tục và tối ưu về thành phần hóa. Vấn đề này đòi hỏi một cái nhìn tổng quát trong kế hoạch khai thác dài hạn của mỏ đá vôi xi măng. Hiện nay, ở Việt Nam 
vấn đề lập kế hoạch khai thác mỏ dài hạn được thực hiện một cách thủ công thông qua bình đồ và các mặt cắt của mỏ và sử dụng các chương trình đồ họa được cài trên máy tính điện tử. Bên cạnh đó, hầu hết các mỏ chỉ quan tâm tới kế hoạch khai thác ngắn hạn, kế hoạch khai thác dài hạn chưa được chú ý.

Đầu vào tiêu chuẩn trong vấn đề lập kế hoạch khai thác mỏ là mô hình khối, mô hình bao gồm các vi khối bao phủ toàn bộ thân khoáng sàng. Mỗi một vi khối chứa đựng đầy đủ những thông tin cụ thể phục vụ cho công tác lập kế hoạch khai thác như: tọa độ của các vi khôi, thông tin về thành phần hóa học, các đặc trưng về chất lượng, hàm lượng các chất,.... Những đặc trưng này được sử dụng để ước lượng giá trị kinh tế cho mỗi vi khối. Giá trị hàm lượng biên được sử dụng để phân biệt quặng và đất đá thải dựa trên giá bán kim loại. Tuy nhiên, việc lập kế hoạch khai thác cho các mỏ đá vôi xi măng không thể dựa trên giá trị kinh tế của các vi khối vì việc sử dụng giá bán của xi măng trên trị trường để gán giá trị kinh tế cho các vi khối là rất phức tạp, cũng như để phân loại quặng và đất đá thải (M.W.A. Asad , 2011). Các giải pháp nhận được từ các phần mềm thương mại, sử dụng giá trị kinh tế của các vi khối là đầu vào của phần mềm để giải quyết vấn đề lập kế hoạch khai thác dài hạn cho các mỏ đá vôi xi măng là không thực tế (M.W.A. Asad , 2011).

Lập kế hoạch khai thác mỏ là các công việc phân cấp, bao gồm ba giai đoạn: dài hạn, trung hạn và ngắn hạn. Lập kế hoạch khai thác mỏ là đi trả lời hai câu hỏi lớn: những vi khối nào được khai thác và khi nào vi khối đó được khai thác trên cơ sở tối ưu hóa lợi nhuận cho mỏ mà vẫn đảm bảo cung cấp đủ nguyên liệu thô cho nhà máy xi măng về khối lượng và chất lượng. Vấn đề tối ưu hóa lập kế hoạch khai thác dài hạn cho phạm vi toàn mỏ là một vấn đề phức tạp và không hề đơn giản bởi quy mô của vấn đề là lớn, bất chấp những tiến bộ trong công nhệ máy tính và các phần mềm trong suốt nhiều thập kỷ qua, một số mô hình toán tối ưu vẫn chưa có lời giải bởi độ lớn của nó. Cách tiếp cận phổ biến nhất hiện nay cho vấn đề lập kế hoạch khai thác dài hạn là phân chia nó thành 3 giai đoạn bao gồm: tối ưu hóa biên giới mỏ lộ thiên, thiết kế các giai đoạn khai thác và lập lịch kế hoạch sản xuất cho các giai đoạn khai thác (K. Dagdelen , 2001; J. Whittle, 1998). Việc xác định biên giới kết thúc của mỏ lộ thiên có thể được giải quyết bằng cách sử dụng các thuật toán quy hoạch dựa trên kinh nghiệm (heuristic) như hình nón động (M. Pana và T. Carlson, 1966), thuật toán dựa trên lý thuyết đồ thị (Lerchs H. và Grossman F., 1965; Y. Zhao, 1992)), hoặc thuật toán Pseudoflow (D.S. Hochbaum và A. Chen, 2000; D.S. Hochbaum, 2008) ) với hàm mục tiêu là tối đa hóa tổng lợi nhuận. Trong khi đó, các thuật toán Heusistic được thảo luận trong (M. Gershon, 1987; M. Lemieux, 1979) thường được sử dụng để thiết kế các giai đoạn khai thác. Cuối cùng, vấn đề lập lịch kế hoạch sản xuất dài hạn có thể được giải quyết bởi bốn mô hình toán học điển hình: lập trình tuyến tính (LP) (T.B. Johnson, 1968), lập trình số nguyên (IP) (R. Chicoisne et al., 1992) , lập trình hỗn hợp số nguyên (MIP) ( H. Askari - Nasab et al., 2011; M. Tabesh và H. Askari - Nasab, 2011) và lập trình số nguyên ngẫu nhiên (SIP) (S. Ramazan, 2007). Để giải quyết các mô hình toán này, nhiều thuật giải đã được phát triển để giải quyết và khắc phục kích thước lớn của mô hình toán tối ưu như: kỹ thuật phân nhánh - giới hạn (L. Caccetta và S.P. Hill, 2003) , các phương pháp Heuristics và Meta Heuristic (M. Gershon, 1987; M. Godoy và R. Dimitrakopoulos, 2004; R. Chicoisne et al., 2012; R. Goodfellow, 2014), các phương pháp gộp và nhóm dũ̃ liệu (M. Tabesh và H. Askari - Nasab, 2011; S. Ramazan, 2007) ). Hiện nay, các kỹ thuật tối ưu hóa trong vấn đề lập kế hoạch khai thác dài hạn vẫn chưa được sử dụng rộng rãi trên các mỏ khai thác đá vôi xi măng. Việc không thể thiết lập mô hình khối kinh tế dựa trên giá bán của xi măng trên thị trường dẫn đến giải pháp cho vấn đề lập kế hoạch khai thác của các mỏ đá vôi xi măng khác với các vấn đề của các mỏ khai thác quặng lộ thiên (K. Dagdelen và M.W. Asad, 2002; S. Srinivasan và D. Whittle, 1996). Hầu hết các giải pháp được đề xuất cho vấn đề lập kế hoạch khai thác dài hạn cho các mỏ đá vôi xi măng là phương pháp Heuristic, và các giải pháp này đều chưa đạt được kết quả mong muốn. Thuật toán sắp sếp (M.W.A. Asad, 2011) được sử dụng để giải quyết vấn đề lập kế hoạch khai thác dài hạn cho các mỏ khai thác đá vôi xi măng. Tuy nhiên, vấn đề tối ưu của thuật giải có thể khó đạt được và mô hình mất đi tính linh hoạt. Mô hình toán tuyến tính số nguyên hỗn hợp được đề xuất để giải quyết vấn đề lập kế hoạch khai thác ngắn hạn cho các mỏ khai thác đá vôi xi măng đã được trình bày trong nghiên cứu (S.U. Rehman và M.W.A. Asad, 2010) . Mô hình lập kế 
hoạch khai thác dài hạn đã được phát triển (D. Joshi, S. Chatterjee và S.M. Equeenuddin, 2015) để cung cấp khối lượng và chất lượng đá vôi phù hợp cho nhà máy xi măng. Để giảm kích thước của bài toán, họ đã áp dụng phương pháp gộp để nhóm các vi khối có cùng vị trí và cùng hệ số bão hòa đá vôi (LSF) để tạo thành một tập hợp các vi khối và sau đó chia nhỏ vấn đề lớn thành các vấn đề nhỏ. Tuy nhiên, chất lượng của giải pháp này cũng không rõ ràng.

Mục đích của nghiên cứu này là phát triển một mô hình toán tối ưu tuyến tính số nguyên hỗn hợp mới để giải quyết vấn đề lịch kế hoạch khai thác dài hạn cho các mỏ đá vôi xi măng. Mục tiêu của mô hình là chi phí để tạo ra hỗn hợp nguyên liệu thô để sản xuất xi măng là tối thiểu, đồng thời mô hình xem xét tổng hợp các vấn đề như: các hoạt động của mỏ, các yêu cầu về phối trộn, khối lượng phụ gia mua ngoài thị trường. Để đạt được mục tiêu nghiên cứu, một phương pháp bao gồm nhiều bước được phát triển giúp giải quyết vần đề lập kế hoạch khai thác dài hạn cho mỏ đá vôi xi măng.

\section{Phương pháp nghiên cứu}

Đầu tiên, các vi khối được nhóm thành các đơn vị khai thác bằng cách sử dụng các thuật toán nhóm, điều này giúp giảm quy mô của vấn đề và phù hợp với thực tế sản xuất. Thứ hai, việc lập kế hoạch khai thác dài hạn cho toàn mỏ đá vôi xi măng được phân chia thành các vấn đề nhỏ hơn, mỗi vấn đề liên quan đến một khoảng thời gian $\mathrm{t}$ $(\mathrm{t}=1, \ldots, \mathrm{T})$ tức là chia thành từng năm khai thác và giải quyết chúng một cách tuần tự. Giải pháp tìm được của thuật toán cung cấp cho mỏ dưới dạng các lời giải có nghiệm ban đầu để giải quyết vấn đề lập kế hoạch toàn mỏ.

\subsection{Kỹ thuật nhóm các vi khối}

Trong nghiên cứu này, các vi khối trong cùng một tầng khai thác được nhóm lại tạo thành các khoảnh khai thác chọn lọc dựa trên các thuộc tính: vị trí, loại đất đá và phân phối hàm lượng của các vi khối. Những khoảnh khai thác này sau đó được đưa vào mô hình lập kế hoạch khai thác. Do đó, thay vì giải quyết vấn đề lập kế hoạch khai thác ở cấp độ vi khối, chúng tôi đã thực hiện ở cấp độ khoảnh khai thác chọn lọc. Kỹ thuật này giúp làm giảm kích thước của bài toán, cho phép tạo ra các giải pháp tối ưu trong thời gian hợp lý và tạo ra kế hoạch khai thác cho các khoảnh, phù hợp với thực tế khai thác. Tuy nhiên, khi tăng kích thước của các khoảnh khai thác đưa vào lập lịch sẽ làm giảm chất lượng của kết quả và làm giảm giá trị NPV hoặc làm tăng chi phí so với lập lịch khai thác trên các vi khối.

\section{Các bước tiến hành kỹ thuật nhóm:}

(i) Bước 1: Xem xét mỗi một vi khối là một khoảnh khai thác chọn lọc và tính toán mức độ tương đồng giữa các vi khối trên cùng một tầng khai thác dựa vào vị trí, loại đất đá và sự phân bố hàm lượng thành phần hóa;

(ii) Bước 2: Liên kết các vi khối với nhau thành mộ khoảnh khai thác mới;

(iii) Bước 3: Tính toán sự tương đồng giữa các khoảnh khai thác mới được thiết lập với các khoảnh khai thác khác còn lại;

(iv) Bước 4: Lặp lại bước ii và iii, tất cả các vi khối được nhóm lại tạo thành những khoảnh khai thác.

Ngoài ra, để được chọn là một khoảnh khai thác cho đầu vào của mô hình lập kế hoạch khai thác dài hạn, những đơn vị này phải có hình dạng và kích thước phù hợp với thực tế khai thác của mỏ (M. Tabesh và H. Askari - Nasab, 2011) . Nhóm tác giả đã lập trình thuật toán trên môi trường Matlab (MATLAB Software) để nhóm các vi khối thành các khoảnh khai thác chọn lọc cũng như tinh chỉnh hình dạng và kích thước của chúng.

\subsection{Mô hình tuyến tính số nguyên hỗn hợp trong công tác lập kế hoạch khai thác dài hạn cho các mỏ đá vôi xi măng}

\subsubsection{Nhũng yêu cầu về phối trộn trong công nghiệp} xi măng

Chìa khóa thành công cho vấn đề lập kế hoạch khai thác dài hạn cho mỏ đá vôi xi măng là đảm bảo cung cấp đầy đủ hỗn hợp nguyên liệu thô cho nhà máy xi măng về khối lượng và chất lượng. Do đó, việc trung hòa đá vôi trong quá trình khai thác đóng một vai trò quan trọng trong việc định hướng kế hoạch khai thác dài hạn của mỏ. Đá vôi được khai thác phải đảm bảo các yêu về tỷ lệ phần trăm thành phần hóa của các oxit như canxi oxit $(\mathrm{CaO})$, silic oxit $\left(\mathrm{SiO}_{2}\right)$, nhôm oxit $\left(\mathrm{Al}_{2} \mathrm{O}_{3}\right)$, oxit sắt $\left(\mathrm{Fe}_{2} \mathrm{O}_{3}\right)$, magie oxit $(\mathrm{MgO})$, kali oxit $\left(\mathrm{K}_{2} \mathrm{O}\right), \ldots$ trong phạm vi chấp nhận được theo công nghệ sản xuất xi măng của nhà máy. 
Trong sản xuất xi măng, việc phát triển hỗn hợp nguyên liệu thô phải đảm bảo cân bằng của các oxit kể trên thông qua các chỉ số sau silica (SR), hệ số bão hòa vôi (LSF) và tỷ lệ alumina (AM) và khoáng clinker bao gồm alit $\left(3 \mathrm{CaO} \cdot \mathrm{SiO}_{2}\right)$ đại diện là " $\mathrm{C}_{3} \mathrm{~S}$ ”, belit $\left(2 \mathrm{CaO} \cdot \mathrm{SiO}_{2}\right)$ đại diện là " $\mathrm{C}_{2} \mathrm{~S}$ ", khoáng canxi aluminat $\left(3 \mathrm{CaO} \cdot \mathrm{Al}_{2} \mathrm{O}_{3}\right)$ đại diện là " $\mathrm{C}_{3} \mathrm{~A}$ ", và khoáng Canxi alumo ferit $\left(4 \mathrm{CaO} \cdot \mathrm{Al}_{2} \mathrm{O}_{3} \cdot \mathrm{Fe}_{2} \mathrm{O}_{3}\right)$ đại diện là " $\mathrm{C}_{4} \mathrm{AF}$ ". Các phương trình từ (1) đến (7) (Rehman và nnk, 2018) biểu diễn các chỉ số này:

$$
\begin{gathered}
\mathrm{SR}=\frac{\mathrm{SiO}_{2}}{\mathrm{AI}_{2} \mathrm{O}_{3}+\mathrm{Fe}_{2} \mathrm{O}_{3}} \\
L S F=\frac{\mathrm{CaO}}{2.8 \mathrm{SiO}_{2}+1.18 \mathrm{AI}_{2} \mathrm{O}_{3}+0.65 \mathrm{Fe}_{2} \mathrm{O}_{3}} \\
\mathrm{AM}=\frac{\mathrm{Al}_{2} \mathrm{O}_{3}}{\mathrm{Fe}_{2} \mathrm{O}_{3}} \\
\mathrm{C}_{3} \mathrm{~S}=4.071 \times \mathrm{CaO}-7.60 \times \mathrm{SiO}_{2}-6.78 \times \\
\mathrm{Cl}_{2} \mathrm{~S}=-3.071 \times \mathrm{OaO}+8.6 \times \mathrm{OiO}_{3}+5.068 \\
\times \mathrm{Al}_{2} \mathrm{O}_{3}-1.079 \times \mathrm{Fe}_{2} \mathrm{O}_{3} \mathrm{O}_{3} \\
\mathrm{C}_{3} \mathrm{~A}=2.65 \times \mathrm{Al}_{2} \mathrm{O}_{3}-1.692 \times \mathrm{Fe}_{2} \mathrm{O}_{3} \\
\mathrm{C}_{4} \mathrm{AF}=3.043 \times \mathrm{Fe}_{2} \mathrm{O}_{3}
\end{gathered}
$$

Trong nghiên cứu này, sự phối trộn nguyên liệu thô tại kho chứa là sự kết hợp của đá vôi được khai thác từ mỏ và các chất phụ gia mua ở ngoài mỏ. Hỗn hợp này phải phù hợp với yêu cầu thực tế trong sản xuất xi măng và được sử dụng để minh họa cách thức làm việc của mồ hình tuyến tính số nguyên hỗn hợp.

\subsubsection{Mô hình tuyến tính số nguyên hỗn hợp}

Trong mô hình tuyến tính số nguyên hỗn hợp, mỗi một tập các vi khối sau khi nhóm được gọi là một khoảnh khai thác. Giá trị hàm lượng của khoảnh khai thác được tính bằng giá trị trung bình hàm lượng của các vi khối tạo thành. Chi phí khai thác và khối lượng của khoảnh khai thác này là tổng chi phí và khối lượng của các vi khối thuộc khoảnh khai thác này. Để giải quyết mô hình, nhóm nghiên cứu đưa ra các giả định sau của mô hình:

(i) Các khoảnh khai thác phải được khai thác toàn bộ khi chúng được lên kế hoạch trong một khoảng thời gian;

(ii) Tất cả các dữ liệu từ mô hình khối địa chất, từ các nguồn phụ gia mua bên ngoài bao gồm: hàm lượng các thành phần hóa, chi phí khai thác, chi phí mua các chất phụ gia là các giá trị xác định và không đổi.

Công thức toán học của mô hình được trình bày như sau:

\section{Các chỉ số của mô hình:}

$i \in I$ : Đơn vị khai thác thứ $i ; j \in N_{i} \subset I$ - Đơn vị khai thác thứ $j$ tiền nhiệm mà cần phải khai thác trước vi khối $i ; t, t^{\prime} \in T$ - Các giai đoạn lập kế hoạch; $a \in A$ - Các chất phụ gia mua bên ngoài mỏ $(a=1$ : sét, $a=2$ cát, $a=3$ : đá vôi, $a=4$ quặng sắt,...); $k \in K$ - Tập các chỉ số hóa học $K\left(k=1: \mathrm{CaO}, k=2: \mathrm{SiO}_{2}\right.$, $k=3: \mathrm{Al}_{2} \mathrm{O}_{3}, k=3: \mathrm{Al}_{2} \mathrm{O}_{3}, k=4: \mathrm{Fe}_{2} \mathrm{O}_{3}, k=5: \mathrm{MgO}$, $\left.k=6: \mathrm{SR}, k=7: \mathrm{LSF}, k=8: \mathrm{AM}, k=9: \mathrm{C}_{3} \mathrm{~S}, \ldots ..\right)$.

\section{Các thông số của mô hình:}

$B_{e}$ - Khối lượng nguyên liệu của vi khối thứ $e$; $C_{i t}$ : Chi phí khai thác của khoảnh khai thác thứ i trong giai $t$; $C_{a t}$ - Chi phí mua chất phụ gia a trong giai đoạn $t ; \min ^{\prime} C_{t}, \max M C_{t}$ - Khối lượng nguyên liệu thô tối thiểu và tối đa được khai thác tại mỏ trong giai đoạn $t$; $\min A_{a t}, \max A_{a t}$ - Khối lượng chất phụ gia $k$ tối thiểu và tối đa được mua từ ngoài mỏ trong giai đoạn $t ; g_{k i}$ - Giá trị hàm lượng trung bình của thành phần hóa $k$ trong đơn vị khai thác $i ; g_{k a}$ - Giá trị hàm lượng trung bình của thành phần hóa $k$ trong chất phụ gia $a ; \min G_{k}, \max G_{k}$ Thành phần hóa $k$ tối thiểu và tối đa cho phép trong hỗn hợp nguyên liệu thô.

\section{Các biến quyết định}

$X_{i t}=1$ nếu khoảnh khai thác $i$ được lên lịch khai thác trong giai đoạn $t$, và bằng 0 trong trường hợp khác; $Y_{a t}$ là khối lượng của phụ gia $a$ mua ngoài thị trường.

Hàm mục tiêu

$$
\text { Minimize } \sum_{t \in T}\left(\sum_{i \in I} C_{i t} X_{i t}+\sum_{a \in A} C_{a t} Y_{a t}\right)
$$

Ràng buộc về trình tự khai thác các khoảnh:

$$
\begin{aligned}
& N_{i} \cdot X_{i t}-\sum_{t^{\prime} \in t} \sum_{j \in N_{i}} X_{j t} \leq 0, \forall i \in I, \forall t \in T \\
& \min M C_{t} \leq \sum_{i \in I} X_{i t} \cdot B_{i} \leq \max M C_{t}, \forall t \in T
\end{aligned}
$$

Ràng buộc về khối lượng chất phụ gia thêm vào: 
$\min A_{a t} \leq A_{a t} \leq \max A_{a t}, \forall t \in T, \forall k \in K$

Ràng buộc về trữ lượng:

$$
\sum_{i \in I} X_{i t} \leq 1, \forall t \in T
$$

Hàm mục tiêu (8) tìm cách giảm chi phí khai thác đến mức tối thiểu để phát triển hỗn hợp nguyên liệu thô cho nhà máy xi măng. Ràng buộc (9) đảm bảo rằng khoảnh khai thác thứ $i$ sẽ không được khai thác trong khoảng thời gian $t$ trừ khi tất cả các khoảnh khai thác $\mathrm{j}$ đã được khai thác hết trong khoảng thời gian $t$. Mối quan hệ về trình tự khai thác giữa các khoảnh khai thác được xác định theo mối quan hệ ưu tiên giữa các vi khối: khoảnh khai thác thứ $j$ cần được khai thác trước khoảnh khai thác thứ $i$ khi và chỉ khi đơn vị khai thác thứ $j$ chứa đựng một vi khối phải khai thác trước khi khai thác một vi khối nào đó trong đơn vị khai thác thứ $i$. Các ràng buộc (10) và (11) đảm bảo sản lượng tối thiểu và tối đa của đá vôi được khai thác từ mỏ và phụ gia được mua từ các nguồn bên ngoài, tương ứng.

Các ràng buộc chất lượng phối trộn nguyên liệu thô như Bảng 1 sau:

Bảng 1. Các công thức ràng buộc chất lượng phối trộn nguyên liệu thô.

\begin{tabular}{|c|c|}
\hline $\min _{k} \leq \frac{\left[\sum_{i \in I} X_{i t} \cdot g_{k i} \cdot B_{i}+\sum_{a \in A} Y_{a t} \cdot g_{k a}\right]}{\left[\sum_{i \in I} X_{i t} \cdot B_{i}+\sum_{a \in A} Y_{a t}\right]} \leq \max G_{k}, \forall t \in T, \forall k \in K$ & (13) \\
\hline 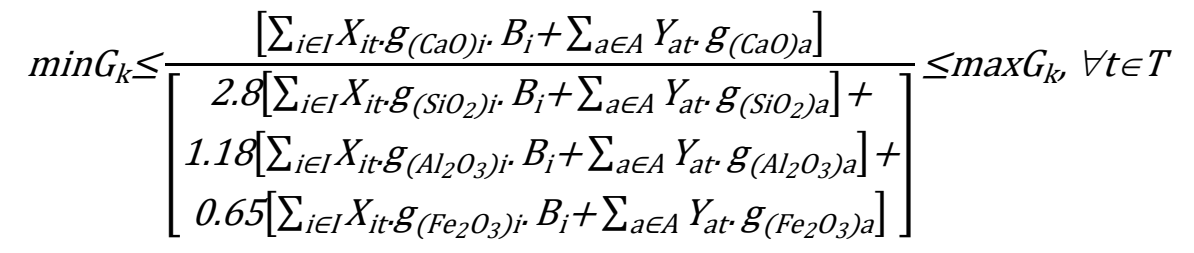 & (14) \\
\hline $\min _{k} \leq \frac{\left[\sum_{i \in I} X_{i t^{*}} \cdot g_{\left(\mathrm{SiO}_{2}\right) i^{*}} B_{i}+\sum_{a \in A} Y_{a t^{*}} g_{\left(\mathrm{SiO}_{2}\right) a}\right]}{\left[\begin{array}{c}\left.\left[\sum_{i \in I} X_{i t} \cdot g_{\left(\mathrm{Al}_{2} \mathrm{O}_{3}\right) i_{i}} \cdot B_{i}+\sum_{a \in A} Y_{a t^{*}} \cdot g_{\left(\mathrm{Al}_{2} \mathrm{O}_{3}\right) a}\right]+\right] \\
{\left[\sum_{i \in I} X_{i t^{*}} g_{\left(\mathrm{Fe}_{2} \mathrm{O}_{3}\right) i_{i}} B_{i}+\sum_{a \in A} Y_{a t^{*}} g_{\left(\mathrm{Fe}_{2} \mathrm{O}_{3}\right) a}\right]}\end{array}\right]} \leq \max G_{k^{\prime}}, \forall t \in T$ & (15) \\
\hline 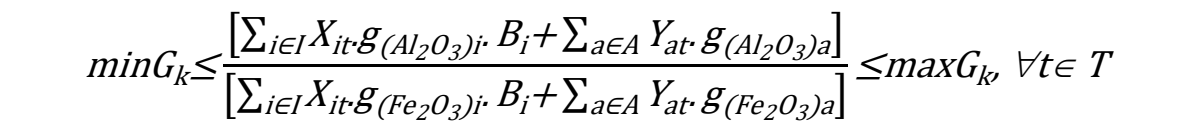 & (16) \\
\hline 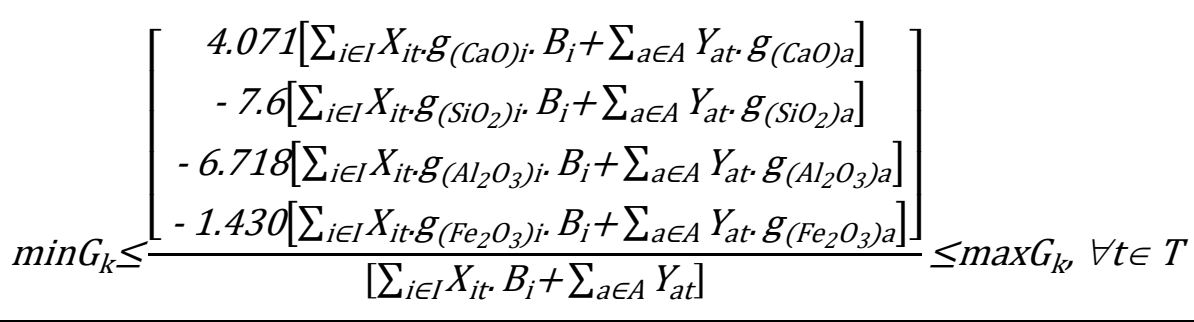 & (17) \\
\hline $\min G_{C} \leq \frac{\left[\begin{array}{l}2.650\left[\sum_{i \in I} X_{i t} \cdot g_{\left(A l_{2} O_{3}\right) i} \cdot B_{i}+\sum_{a \in A} Y_{a t} \cdot g_{\left(A l_{2} O_{3}\right) a}\right] \\
-1.692\left[\sum_{i \in I} X_{i t} \cdot g_{\left(F e_{2} O_{3}\right) i} \cdot B_{i}+\sum_{a \in A} Y_{a t} \cdot g_{\left(F e_{2} O_{3}\right) a}\right]\end{array}\right.}{\left[\sum_{i \in I} X_{i t} B_{i}+\sum_{a \in A} Y_{a t}\right]} \leq \max G_{C}, \forall t \in T$ & (18) \\
\hline 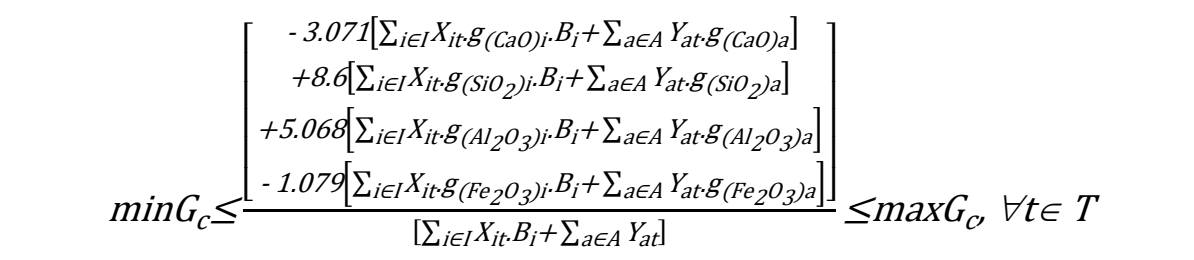 & $(19)$ \\
\hline
\end{tabular}


\begin{tabular}{|c|c|}
\hline $\min G_{c} \leq \frac{3.043\left[\sum_{i \in I} X_{i t} g_{\left(\mathrm{Fe}_{2} \mathrm{O}_{3}\right)} \cdot B_{i}+\sum_{a \in A} Y_{a t} g_{\left(\mathrm{Fe}_{2} \mathrm{O}_{3}\right) a}\right]}{\left[\sum_{i \in I} X_{i t} B_{i}+\sum_{a \in A} Y_{a t}\right]} \leq \max G_{c}, \forall t \in T$ & (20) \\
\hline $\begin{array}{c}\text { Các ràng buộc định nghĩa biến quyết định: } \\
X_{i t} X_{j t} \in\{0,1\} ; Y_{a t} \geq 0, \forall t \in T, \forall i \in I, \forall a \in A\end{array}$ & (21) \\
\hline
\end{tabular}

Ràng buộc (12) đảm bảo rằng một khoảnh khai thác chỉ được khai thác trong một lần duy nhất. Các ràng buộc (13) - (21) là các ràng buộc về yêu cầu phối trộn của nguyên liệu thô. Các ràng buộc (13) yêu cầu giá trị hàm lượng trung bình của các oxit $\mathrm{CaO}, \mathrm{SiO}_{2}, \mathrm{Al}_{2} \mathrm{O}_{3}, \mathrm{Fe}_{2} \mathrm{O}_{3}$, and $\mathrm{MgO}, \ldots$ phải ở giữa mức tối thiểu và tối đa trong mỗi khoảng thời gian lập kế hoạch. Để duy trì cân bằng của các oxit trong hỗi hợp nguyên liệu thô, các ràng buộc (14) - (19) duy trì các chỉ số LSF, SR, AM, $\mathrm{C}_{3} \mathrm{~S}, \mathrm{C}_{3} \mathrm{~A}$, và $\mathrm{C}_{4} \mathrm{AF}$ trong giới hạn mong muốn. Cuối cùng, các ràng buộc (21) đảm bảo các biến quyết định là nguyên và không âm.

\subsection{Phương pháp giải}

Trong cách giải quyết mô hình tuyến tính số nguyên hỗn hợp được đề suất trong phần trước, sản lượng mỏ được xác định theo ràng buộc (10), thể hiện những thuộc tính chung của bài toán xếp balo (bài toán Knapsack). Đây là một bài toán NP hard (là một tập hợp các bài toán trong lý thuyết độ phức tạp tính toán), điều đó có nghĩa giải pháp tối ưu của vấn đề lập kế hoạch khai thác dài hạn cho các mỏ đá vôi xi măng không thể có được trong thời gian tính toán thực. Do đó, để giải quyết vấn đề này nhóm nghiên cứu đã áp dụng các phương pháp khử biến và phương pháp Heuristics nhằm giảm thời gian giải quyết và thu được các giải pháp cận tối ưu cho vấn đề lập kế hoạch khai thác dài hạn cho các mỏ đá vôi xi măng.

\subsubsection{Phương pháp khư biến quyết định}

Để giảm kích thước của bài toán, tác giả áp dụng các khái niệm về thời thời gian bắt đầu sớm nhất và muộn nhất cho mỗi một khoảnh khai thác để khử các biến nhị phân quyết định trong mô hình (I. Uublicatim Dciooer,2003; M.P. Gaupp, 2008; N. Boland, C. Fricke và G. Froyland, 2007). Thời gian bắt đầu sớm nhất tức là mất bao nhiêu thời gian để bắt đầu khai thác khoảnh khai thác thứ $i$ dựa trên thứ tự khai thác và sản lượng lớn nhất của mỏ. Các khoảnh khai thác ưu tiên được xác định là một hình nón nằm phía trên khoảnh khai thác thứ $i$, hình nón này cần phải được khai thác hết trước khi khai thác khoảnh khai thác thứ $i$. Khối lượng của hình nón và tổng sản lượng khai thác mỏ lớn nhất từ giai đoạn đầu tiên đến giai đoạn $\mathrm{t}$ được tính toán và so sánh với nhau. Nếu tổng khối lượng của hình nón vượt lớn hơn sản lượng khai thác lớn nhất của mỏ, thì thời gian bắt đầu sớm cho đơn vị khai thác $i$ là giai đoạn $t$. Tất cả các biến quyết định tương ứng khi thu hồi đơn vị khai thác thứ $i$ trong các khoảng thời gian trước khoảng thời gian $t$ phải bằng 0 trong giải pháp tối ưu và do đó chúng ta có thể khử các biến này khỏi bài toán.

Trong khi đó, thời gian bắt đầu muộn nhất để thu hồi khoảnh khai thác thứ i phản ánh thời gian lâu nhất để có thể khai thác khoảnh khai thác này dựa trên thứ tự khai thác và sản lượng mỏ tối thiểu. Trong trường hợp này, khoảnh khai thác ưu tiên là hình nón kế tiếp bên dưới khoảnh khai thác thứ $i$, hình nón này chỉ có thể được khai thác sau khi khoảnh khai thác thứ $i$ được khai thác hoàn toàn. Khối lượng của hình nón được sử dụng để tính toán khối lượng của các khoảnh khai thác còn lại trong mỏ, đây là khối lượng khai thác lớn nhất để thu được khoảnh khai thác thứ $i$. Tổng sản lượng khai thác tối thiểu cộng dồn từ giai đoạn $t$ đến khi kết thúc khai thác được tính toán và so sánh với khối lượng của các khoảnh khai thác còn lại. Nếu khối lượng của các khoảnh khai thác còn lại thấp hơn tổng sản lượng tích lũy tối thiểu, thời gian bắt đầu muộn nhất cho đơn vị khai thác thứ i là giai đoạn $t+1$. Tất cả các biến quyết định tương ứng với việc thu hồi khoảnh khai thác thứ i tại thời điểm này hoặc sau thời gian bắt đầu muộn nhất được đặt giá trị 1 trong giải pháp tối ưu của thuật toán. Các hình nón trước hoặc hình nón tiếp theo của đơn vị khai thác thứ $i$ được thể hiện trong Hình 1.

\subsubsection{Lời giải có nghiệm ban đầu}

Một phương pháp khác để giảm thời gian giải quyết mô hình tuyến tính số nguyên hỗn hợp là cung cấp lời giải có nghiệm ban đầu. Một giải pháp 


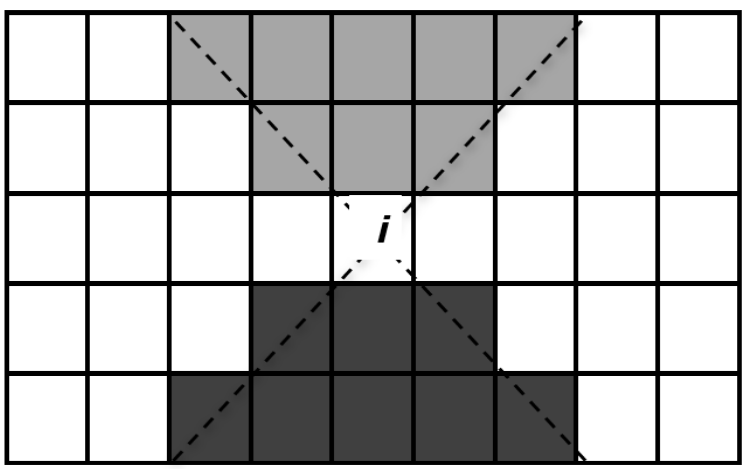

Hình 1. Hình nón trước (mầu sáng) và hình nón tiếp theo (mầu tối) của đơn vị khai thác thứ $i$.

như vậy có thể ngăn việc ước lượng các giải pháp chiếm ưu thế và cho phép sử dụng công cụ tìm kiếm tối ưu cục bộ Heuristic (IBM, 2009). Một số phương pháp Heuritis được sử dụng để nhận dạng lời giải có nghiệm ban đầu như thuật toán "greedy heuristic" (R. Chicoisne, 2012) hay thuật toán Sliding Window Heuristic (C. Cullenbine, R.K. Wood và $A$. Newman, 2011) . Trong nghiên cứu này, chúng tôi xác định lời giải có nghiệm ban đầu bằng cách chia vấn đề vấn đề lập kế hoạch khai thác dài hạn cho các mỏ đá vôi xi măng thành các vấn đề phụ nhỏ hơn theo khoảng thời gian $\mathrm{t}(\mathrm{t} \in \mathrm{T})$ và giải quyết chúng tuần tự theo thứ tự tăng dần của t. Các khoảnh khai thác được chỉ định cho từng vấn đề phụ được loại bỏ khỏi mô hình khối sau khi giải và những đơn vị khai thác còn lại được gán cho giai đoạn tiếp theo. Kích thước của mỗi vấn đề phụ nhỏ hơn đáng kể so với vấn đề lập kế hoạch khai thác dài hạn cho toàn mỏ và do đó, một phương pháp chính xác có thể được sử dụng để giải quyết các vấn đề phụ. Cuối cùng, các phần lời giải có nghiệm của các vấn đề phụ được liên kết với nhau để tạo ra lời giải có nghiệm ban đầu. Nếu giá trị của lời giải có nghiệm ban đầu gần với giới hạn trên $(<a$ - một giá trị GAP được xác định trước) xuất pháp từ sự nới lỏng tuyến tính trong việc giải quyết vấn đề lập kế hoạch dài hạn cho các mỏ đá vôi xi măng, lời giải sẽ trả về lời giải có nghiệm ban đầu. Mặt khác, công cụ giải tiếp tục cải thiện chất lượng của các lời giải có nghiệm ban đầu.

\section{Kết quả nghiên cứu và thảo luận}

Mô hình tuyến tính số nguyên hỗn hợp được triển khai áp dụng tại tại mỏ đá vôi xi măng Tà Thiết - Bình Phước cung cấp nguyên liệu thô cho nhà máy xi măng Bình Phước. Khu vực nghiên cứu có đặc điểm có độ dốc nhẹ từ Tây sang Đông. Các thành tạo đá chính gặp phải trong khu vực bao gồm đá mácnơ có hàm lượng thấp, đá vôi có hàm lượng cận hàm lượng biên và đá vôi có hàm lượng cao. Đá mácnơ có hàm lượng Cao thấp $(\mathrm{CaO}$ $<36 \%$ ) và đá vôi có hàm lượng cận hàm lượng biên $(36 \% \leq \mathrm{CaO} \leq 40 \%)$ không thể được sử dụng để sản xuất xi măng và được đổ vào bãi thải, dẫn đến tăng chi phí khai thác và tổn thất tài nguyên. Hiện tại, công ty đang sử dụng phần mềm Surpac để xây dựng mô hình khối với 22216 vi khối với kích thước mỗi vi khối là $25 \times 25 \times 10 \mathrm{~m}$. Bảng 2 trình bày những đặc trưng thống kê trong mô hình khối của thân khoáng sàng, hàm lượng $\mathrm{CaO}$ phân bố tại tầng +145 m được thể hiện trong Hình 2(a). Để sản xuất xi măng, nhà máy xi măng Bình Phước sử dụng đất sét, cát, đá vôi chất lượng cao và quặng sắt được mua từ các nhà cung cấp khác nhau làm phụ gia để pha trộn với các nguyên liệu thô từ mỏ đá nhằm đạt được các yêu cầu về chất lượng và số lượng cần thiết theo công nghệ sản xuất xi măng.

Để giảm số lượng các biến quyết định trong mô hình tuyến tính số nguyên hỗn hợp, tác giả đã sử dụng thuật toán gộp để nhóm các vi khối thành các khoảnh khai thác dựa trên vị trí và sự phân bố hàm lượng. Thuật toán gộp được mã hõa và phát triển trên môi trường Matlab sử dụng các tùy chọn kích thước cụm trung bình khác nhau: 10, 20, 30, 40,50 và 100 vi khối cho một nhóm. Hình 2(b) minh họa kết quả của việc nhóm tại tầng $+145 \mathrm{~m}$ với kích thước trung bình của nhóm là 30 vi khối. Những đơn vị khai thác được tạo ra phải tuân thủ 3 ràng buộc chính: tính đồng nhất về hàm lượng và loại đất đá, hình dạng có thể khai thác được và kích thước hợp ký để có thể lên lịch kế hoạch khai thác thực tế cho mỏ. Ban đầu, mô hình mô hình tuyến tính số nguyên hỗn hợp cần 444320 biến nhị phân là số vi khối trong mô hình thân khoáng sàng, với số lượng biến lớn như vậy việc tối ưu hóa là không thể tại thời điểm hiện tại. Với việc áp dụng thuật toán nhóm, số lượng biến của mô hình giảm đáng kể như được đưa ra tại Bảng 4 cho phép mô hình mô hình tuyến tính số nguyên hỗn hợp có thể dễ dàng xử lý.

Phần mềm Matlab cũng được sử dụng để chuẩn bị các ma trận ràng buộc, các biến và hàm mục tiêu. Matlab cũng được sử dụng để gọi bộ giải để chạy mã và giải mô hình mô hình tuyến tính số 
Bảng 2. Nhưng thống kê cơ bản của phân phối hàm lượng trong mô hình khối của mỏ.

\begin{tabular}{|c|c|c|c|c|c|c|c|c|}
\hline Giá trị & $\mathrm{CaO}$ & $\mathrm{SiO}_{2}$ & $\mathrm{Al}_{2} \mathrm{O}_{3}$ & $\mathrm{Fe}_{2} \mathrm{O}_{3}$ & $\mathrm{LOI}$ & $\mathrm{MgO}$ & $\mathrm{Na}_{2} \mathrm{O}$ & $\mathrm{K}_{2} \mathrm{O}$ \\
\hline Trung bình & 46,01 & 5,25 & 1,30 & 0,44 & 39,49 & 1,67 & 0,08 & 0,21 \\
\hline Trung vị & 49,26 & 5,67 & 1,42 & 0,45 & 40,53 & 1,68 & 0,07 & 0,18 \\
\hline Phương sai & 65,40 & 4,45 & 0,28 & 0,02 & 44,27 & 0,19 & 0,01 & 0,01 \\
\hline
\end{tabular}
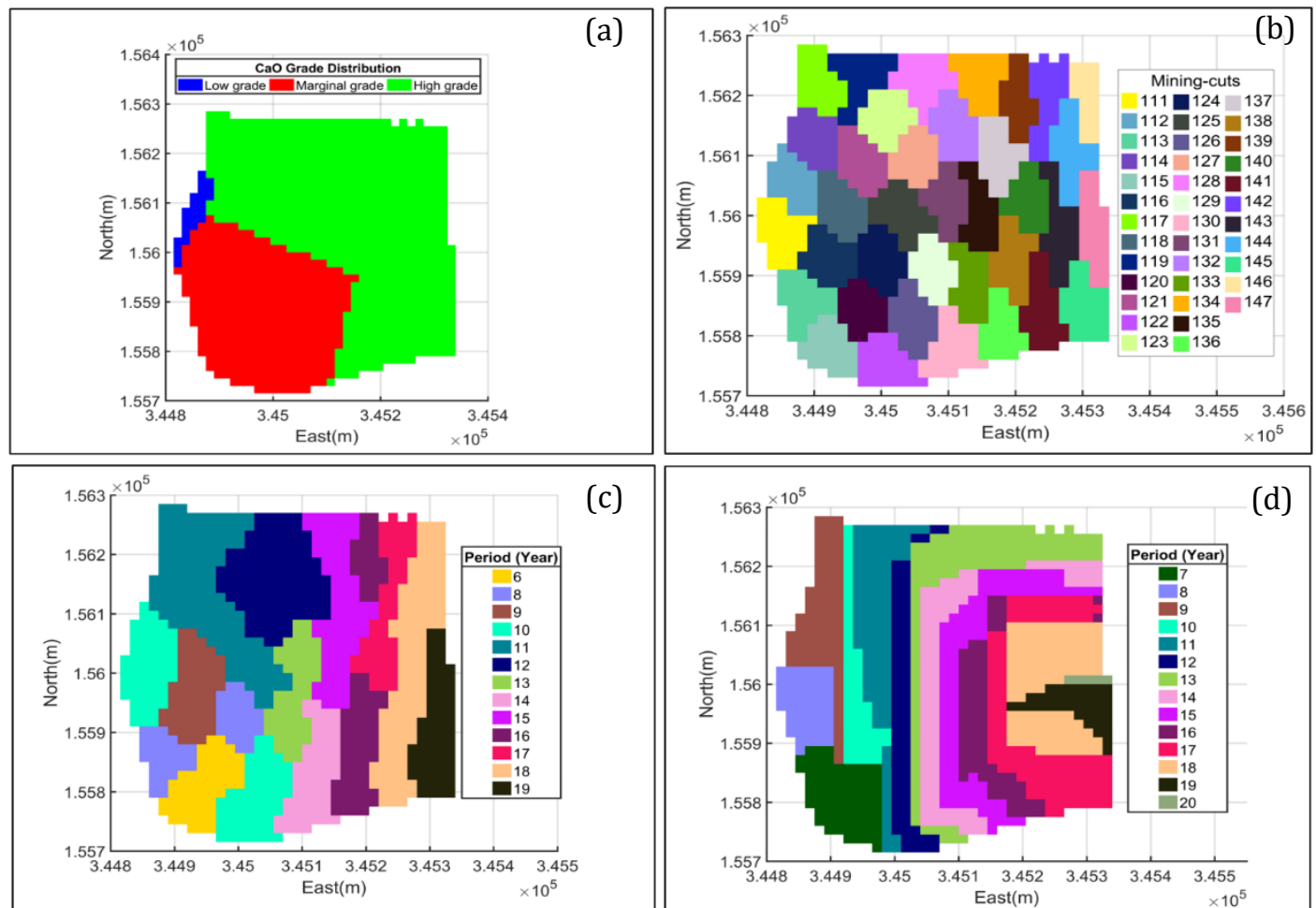

(c)

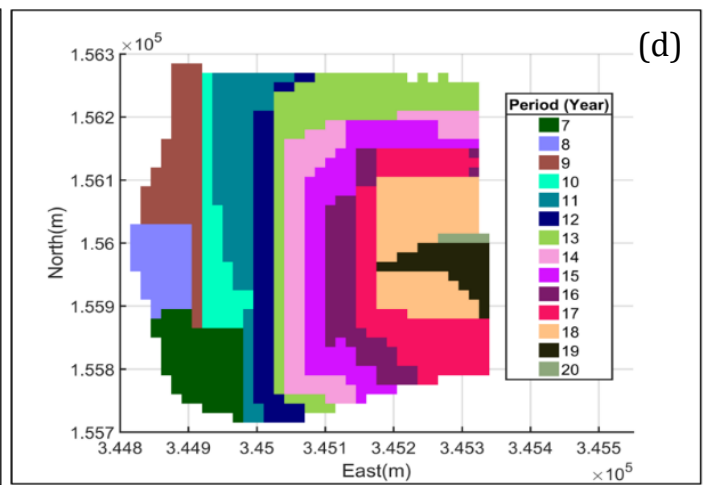

Hình 2. Bình đồ mỏ tại tầng $+145 m$.

(a) Phân bố hàm lượng CaO; (b) Kết quả nhóm 30 vi khối thành các khoảnh khai thác trung bình; (c) Lịch kê hoạch khai thác khi sử dụng mô hình tuyến tính số nguyên hỗn hợp với kích thước trung bình của các khoảnh khai thác là 30 vi khối; (d) Lịch kế hoạch khai thác khi sử dụng phần mềm GEOVIA Minesched.

nguyên hỗn hợp. Bộ giải bắt đầu với việc giải một mô hình tuyến tính nới lỏng, trong đó các biến số nguyên được nới lỏng thành các biến số thực. Sau đó, bộ giải đã sử dụng thuật toán phân nhánh và giới hạn để tìm kiếm giải pháp khả thi số nguyên. Phần code của thuật toán được chạy trên máy tính Dell Precision M4800 lõi tứ kép tốc độ $2,70 \mathrm{GHz}$ với 32 GB RAM. Các yêu cầu ràng buộc đối với vấn đề lập kế hoạch khai thác dài hạn mỏ đá vôi xi măng được tóm tắt trong Bảng 3.

Phương pháp giải của nghiên cứu này yêu cầu hai bước:

Bước 1: tạo ra lời giải có nghiệm ban đầu bằng cách sử dụng thuật toán Heuristic được mô tả ở phần 4.2;

Bước 2: giải quyết mô hình mô hình tuyến tính số nguyên hỗn hợp bằng lời giải có nghiệm ban đầu.
Bảng 3. Các ràng buộc đối với vấn đề lập kế hoạch khai thác dài hạn mỏ đá vôi xi măng.

\begin{tabular}{|l|c|c|}
\hline \multicolumn{1}{|c|}{ Hạn mức } & Tối thiểu & Tối đa \\
\hline Công suất mỏ (triệu tấn) & 3,3 & 4 \\
\hline Khối lượng phụ gia (triệu tấn) & 0 & 1 \\
\hline $\mathrm{CaO}(\%)$ & 62 & 69 \\
\hline $\mathrm{SiO}_{2}(\%)$ & 17 & 26 \\
\hline $\mathrm{Al}_{2} \mathrm{O}_{3}(\%)$ & 4 & 10 \\
\hline $\mathrm{Fe}_{2} \mathrm{O}_{3}(\%)$ & 0,1 & 5 \\
\hline $\mathrm{MgO}, \mathrm{Na}_{2} \mathrm{O}, \mathrm{K}_{2} \mathrm{O}(\%)$ & 0 & 5 \\
\hline $\mathrm{SR}$ & 2 & 2.6 \\
\hline $\mathrm{LSF}$ & 0,9 & 1 \\
\hline $\mathrm{AM}$ & 1 & 3 \\
\hline $\mathrm{C}_{3} \mathrm{~S}(\%)$ & 40 & 60 \\
\hline $\mathrm{C}_{3} \mathrm{~A}(\%)$ & 5 & 15 \\
\hline $\mathrm{C}_{4} \mathrm{AF}(\%)$ & 10 & 18 \\
\hline
\end{tabular}


Mất một vài phút để có được lời giải có nghiệm ban đầu bằng cách sử dụng phương pháp giải chính xác. Bảng 4 biểu diễn tóm tắt mô hình tuyến tính số nguyên hỗn hợp chạy trên các kích thước nhóm khác nhau với việc sử dụng và khôngsử dụng lời giải có nghiệm ban đầu. Bộ giải sẽ dừng nếu mô hình có GAP nhỏ hơn 1\% hoặc thời gian giải đạt tới $12 \mathrm{~h}$. Tất cả các kịnh bản ban đầu sử dụng kỹ thuật loại bỏ biến quyết định. Theo Bảng 4, nhận thấy mô hình không sử dụng lời giải có nghiệm ban đầu việc giải quyết mô hình theo các kịch bản thường ở trường hợp thời gian tới hạn. Trong khi đó mô hình toán với lời giải có nghiệm ban đầu mô hình đã được giải quyết thành công trong tất cả các kịch bản trong khoảng GAP 1\%, điều đó cho thấy phương pháp Heuristic tạo ra một giải pháp tốt với thời gian giải quyết mô hình dài nhất chỉ khoảng $1 \mathrm{~h}$. Mặt khác, qua nhiều lần chạy với các kích thước của khoảnh khai thác khác nhau đã chứng minh khả năng của mô hình tuyến tính số nguyên hỗn hợp trong việc kiểm soát số lượng đơn vị khai thác được tạo ra và thời gian để có được các giải pháp.
Lich kế hoach khai thác được tao ra bởi mô hình tuyến tính số nguyên hỗn hợp đươơ so sánh với lịch kế hoạch khai thác do phần mềm GEOVIA Minesched tạo ra, đây là phần mềm lập kế hoạch sản xuất được sử dụng rộng rãi trong khai thác mỏ đá vôi xi măng. Tất cả các lịch kế hoạch sản xuất được phát triển bởi mô hình tuyến tính số nguyên hỗn hợp và GEOVIA Minesched đã được thực hiện theo cùng đầu vào và cùng một chiến lược khai thác với mục tiêu giảm thiểu chi phí để phát triển hỗn hợp thô trong sản xuất xi măng trong 20 năm. Lịch kế hoạch được tạo ra bởi mô hình tác giả phát triển sử dụng kích thước trung bình của nhóm là 30 vi khối và của GEOVIA Minesched tại tầng +145m được thể hiện tại Hình 2 (c, d), tương ứng. Hình $3(\mathrm{a}, \mathrm{b})$ minh họa các mặt cắt nam - bắc 156142,5 m của lịch kế hoạch khai thác, cho thấy sự khác biệt trong trình tự khai thác giữa chúng.

Lịch kế hoạch khai thác do mô hình tuyến tính số nguyên hỗn hợp mang lại có mức chi phí tạo ra hỗn hợp thô nhỏ hơn $3,17 \div 3,96 \%$ so với lịch kế hoạch khai thác được xây dựng bởi phần mềm

Bảng 4. Kết quả chạy mô hình tuyến tính số nguyên hỗn hợp với các trường hợp kích thước của các khoảnh khai thác khi sử dụng lời giải có nghiệm ban đầu và không sử dụng lời giải có nghiệm ban đầu.

\begin{tabular}{|c|c|c|c|c|c|c|c|c|c|}
\hline \multirow[b]{2}{*}{$\begin{array}{l}\text { Trường } \\
\text { hợp }\end{array}$} & \multirow{2}{*}{$\begin{array}{l}\text { Kích thước } \\
\text { trung bình } \\
\text { của khoảnh } \\
\text { khai thác }\end{array}$} & \multirow{2}{*}{$\begin{array}{c}\text { Số lượng } \\
\text { các } \\
\text { khoảnh } \\
\text { khai thác }\end{array}$} & \multirow{2}{*}{$\begin{array}{l}\text { Số lượng } \\
\text { các biến } \\
\text { nhị phân }\end{array}$} & \multicolumn{3}{|c|}{$\begin{array}{c}\text { Mô hình không sử dụng lời giải } \\
\text { có nghiệm ban đầu }\end{array}$} & \multicolumn{3}{|c|}{$\begin{array}{c}\text { Mô hình sử dụng lời giải có } \\
\text { nghiệm ban đầu }\end{array}$} \\
\hline & & & & $\begin{array}{l}\text { Giá trị của } \\
\text { hàm mục } \\
\text { tiêu }(\$)\end{array}$ & $\begin{array}{c}\text { Giá trị GAP } \\
\text { của mô } \\
\text { hình }(\%)\end{array}$ & $\begin{array}{c}\text { Thời } \\
\text { gian giải } \\
\text { quyết (s) }\end{array}$ & $\begin{array}{c}\text { Giá trị của } \\
\text { hàm mục } \\
\text { tiêu }(\$)\end{array}$ & $\begin{array}{l}\text { Giá trị GAP } \\
\text { của mô } \\
\text { hình }(\%)\end{array}$ & $\begin{array}{c}\text { Thời } \\
\text { gian giải } \\
\text { quyết (s) }\end{array}$ \\
\hline I & 10 & 2446 & 48920 & $\mathrm{~N} / \mathrm{A}$ & $\mathrm{N} / \mathrm{A}$ & $\mathrm{N} / \mathrm{A}$ & 190053700 & 0.05 & 3133 \\
\hline II & 20 & 1276 & 25520 & $\mathrm{~N} / \mathrm{A}$ & N/A & $\mathrm{N} / \mathrm{A}$ & 190120000 & 0.09 & 777 \\
\hline III & 30 & 960 & 19200 & $\mathrm{~N} / \mathrm{A}$ & $\mathrm{N} / \mathrm{A}$ & $\mathrm{N} / \mathrm{A}$ & 190149000 & 0.07 & 418 \\
\hline IV & 40 & 648 & 12960 & $\mathrm{~N} / \mathrm{A}$ & $\mathrm{N} / \mathrm{A}$ & $\mathrm{N} / \mathrm{A}$ & 190250000 & 0.14 & 167 \\
\hline $\mathrm{V}$ & 50 & 526 & 10520 & $\mathrm{~N} / \mathrm{A}$ & $\mathrm{N} / \mathrm{A}$ & $\mathrm{N} / \mathrm{A}$ & 190330000 & 0.17 & 119 \\
\hline VI & 100 & 268 & 5360 & $\mathrm{~N} / \mathrm{A}$ & $\mathrm{N} / \mathrm{A}$ & $\mathrm{N} / \mathrm{A}$ & 191610000 & 0.84 & 103 \\
\hline
\end{tabular}

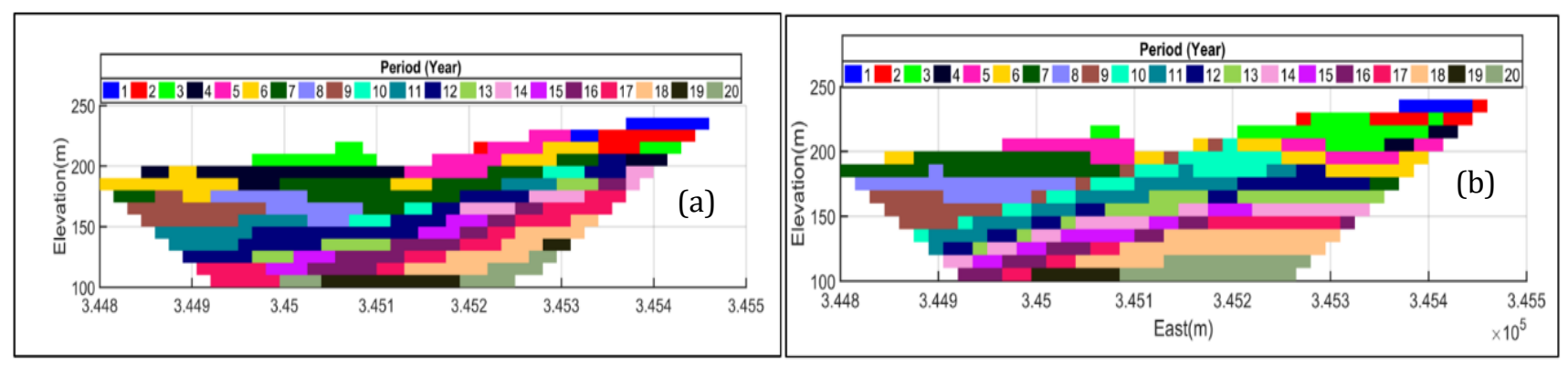

Hình 3. Mặt cắt hướng bắc-nam 156142,5 m

(a) Lịch kế hoạch khai thác khi sử dụng mồ hình tuyến tính số nguyên hỗn hợp với kích thước trung bình của các khoảnh khai thác là 30 vi khối; (b) Lịch kếhoạch khai thác khi sử dụng phần mềm GEOVIA Minesched. 
GEOVIA Minesched trong tất cả các trường hợp, tương đương tiết kiệm khoảng 6,2 $\div$ 7,8 triệu USD, đây là số tiền đáng kể với một mỏ đá nhỏ.

Chi phí cần thiết để tạo ra một tấn nguyên liệu thô trong lịch kế hoạch khai thác của mô hình tuyến tính số nguyên hỗn hợp nhỏ hơn so với kế hoạch khai thác của GEOVIA, ngoại trừ trong trường hợp V. Hình 4 (a), (b) cho thấy sản lượng khai thác hàng năm và lượng phụ gia được mua trong 20 năm trong lịch kế hoạch khai thác của mô hình tác giả phát triển và phần mềm GEOVIA. Sản lượng mỏ và lượng phụ gia được trình bày trong Bảng 3 thỏa mãn trong cả hai lịch kế hoạch khai thác tạo được. Điều đặc biệt đáng chú ý là GEOVIA Minesched yêu cầu mua tất cả các loại phụ gia trong 20 năm trong khi đó mô hình được trình bày trong bài báo chỉ cần đất sét và quặng sắt trong cùng một khoảng thời gian tương tự. Sự so sánh về chất lượng hỗn hợp thô giữa lịch kế hoạch sản xuất được tạo ra từ mô hình nghiên cứu với các tùy chọn về kích thước trung bình của các khoảnh khai thác và lịch sản xuất của GEOVIA được đưa ra trong Hình 5. Qua đó ta thấy mô hình nghiên cứu có khả năng làm thỏa mãn được tất cả các yêu cầu chất lượng hỗn hợp thô với kích thước trung bình của các khoảnh khai thác khác nhau. Trong khi đó, phương pháp GEOVIA Minesched cho thấy sự vi phạm các ràng buộc chất lượng hầu hết các trường hợp, ngoại trừ các ràng buộc về hàm lượng MgO.

\section{Kết luận}

Kỹ thuật tối ưu hóa lịch kế hoạch khai thác đã không được áp dụng rộng rãi trong khai thác mỏ đá vôi xi măng. Việc thực xây dựng lịch kế hoạch khai thác dài hạn cho các mỏ đá vôi xi măng bằng cách sử dụng các giá trị thương mại của vi khối là không đáng tin cậy và không thực tế.

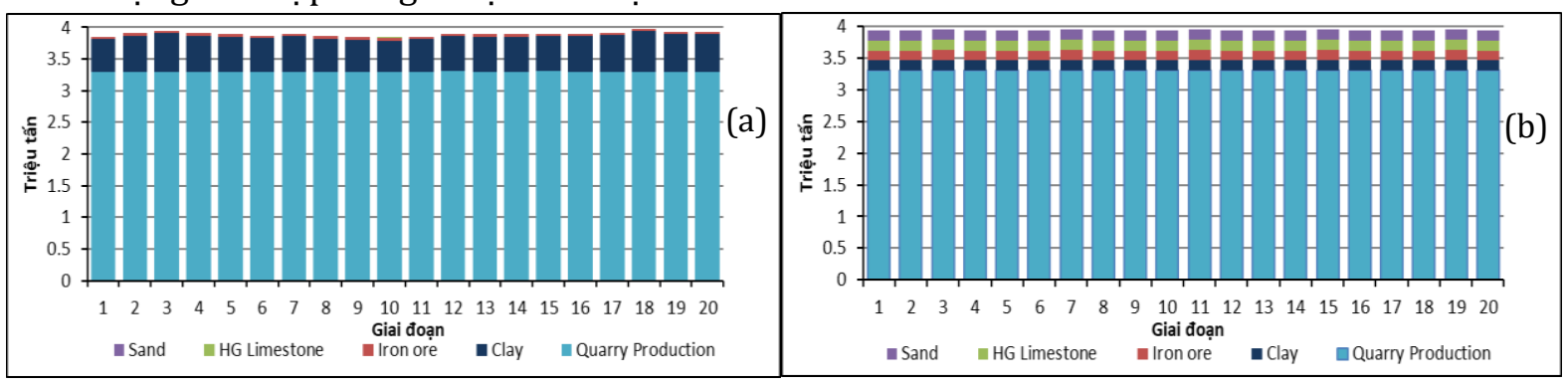

Hình 4. So sánh kế hoạch sản lượng và lượng chất phụ gia cần mua hàng năm. (a) Sử dụng thuật toán đề xuất; (b) Sử dụng phần mềm GEOVIA Minesched.

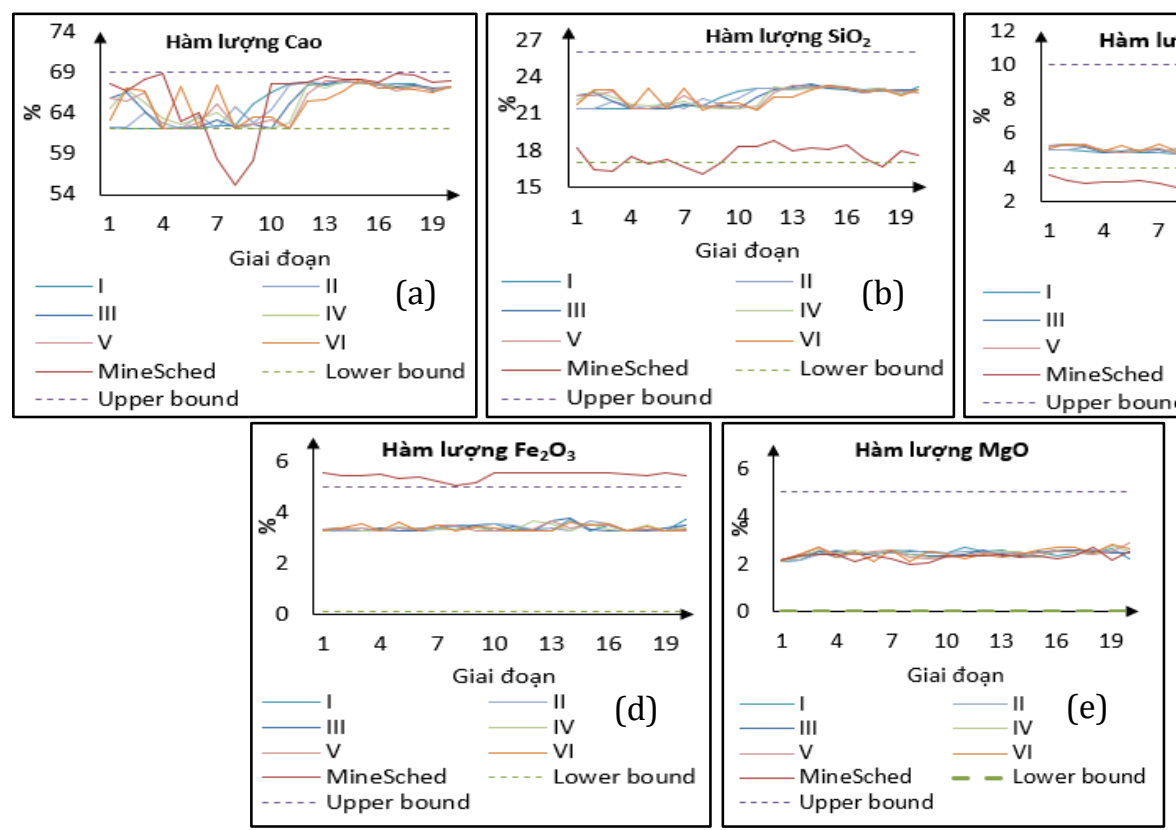

Hình 5. So sánh chất lượng hỗn hợp nguyên liệu thô giữa thuật toán đề xuất và phần mềm GEOVIA Minesched. (a) Hàm lượng Cao; (b) Hàm lượng $\mathrm{SiO}_{2}$; (c) Hàm lượng $\mathrm{Al}_{2} \mathrm{O}_{3}$; (d) Hàm lượng $\mathrm{Fe}_{2} \mathrm{O}_{3}$; (e) Hàm lượng $\mathrm{MgO}$. 
Mô hình tuyến tính số nguyên hỗn hợp đã được sử dụng hiệu quả để giải quyết các vấn đề lập kế hoạch khai thác mỏ. Tuy nhiên, quy mô của vấn đề lập kế hoạch khai thác mỏ trong thực tế vẫn là một thách thức lâu dài. Nghiên cứu này phát triển một mô hình tuyến tính số nguyên hỗn hợp mới tích hợp tối ưu hóa kế hoạch khai thác dài hạn cho các mỏ đá vôi xi măng để cung cấp nguyên liệu thô bền vững cho sản xuất xi măng với chi phí tối thiểu. Để giảm kích thước bài toán, tác giả đã sử dụng thuật toán gộp để nhóm các vi khối thành các khoảnh khai thác. Các khoảnh khai thác được coi là đầu vào cho mô hình tuyến tính số nguyên hỗn hợp. Việc giải quyết mô hình được thực hiện trong hai bước chính: tạo lời giải có nghiệm ban đầu bằng phương pháp Heuristic và cung cấp cho thuật giải cho lời giải có nghiệm ban đầu.

Kết quả áp dụng thực tế mô hình tại mỏ khai thác đá vôi xi măng Tà Thiết cho thấy rằng việc sử dụng thuật toán nhóm các vi khối với nhau không chỉ làm giảm đáng kể số lượng biến nhị phân trong mô hình tuyến tính số nguyên hỗn hợp mà còn tạo ra các lịch kế hoạch khai thác thực tế hơn dựa trên khoảnh khai thác chọn lọc. Phương pháp Heuristic dựa trên kỹ thuật phân tách đã nhanh chóng xác định lời giải có nghiệm ban đầu. Theo kết quả áp dụng tại mỏ, việc giải quyết mô hình bằng các lời giải có nghiệm ban đầu có thể đảm bảo tạo ra các giải pháp tốt hơn.

Trong trường hợp giải quyết mô hình tuyến tính số nguyên hỗn hợp sử dụng lời giải có nghiệm ban đầu thì các vấn đề không thể khắc phục được của mô hình được giải quyết một cách đơn giản hơn và nhanh hơn so với khi không áp dụng. Những kết quả này chứng minh rằng phương pháp giải được đề xuất trong bài viết này có thể vượt qua thách thức về quy mô vấn đề của mô hình tuyến tính số nguyên hỗn hợp trong việc giải quyết vấn đề lập kế hoạch khai thác dài hạn cho các mỏ đá vôi xi măng.

Mô hình tác giả phát triển đã được chứng minh và đánh giá thực tế khi áp dụng và so sánh với một trong những phần mềm thương mại phổ biến trong khai thác mỏ - GEOVIA Minesched. Phân tích cho thấy rằng việc áp dụng mô hình mới này giúp tiết kiệm chi phí đáng kể so với GEOVIA Minesched. Bên cạnh khả năng tối ưu hóa mục tiêu, mô hình cũng xem xét đồng thời các ràng buộc pha trộn nguyên liệu thô, trong khi GEOVIA Minesched nhằm đáp ứng các mục tiêu sản lượng nhưng đã vi phạm các mục tiêu chất lượng trong hầu hết các trường hợp. Điều này nhấn mạnh tầm quan trọng của việc áp dụng các kỹ thuật tối ưu hóa trong việc giải quyết vấn đề lập kế hoạch khai thác dài hạn cho các mỏ đá vôi xi măng.

\section{Đóng góp của các tác giả}

Tác giả Trần Đình Bão hình thành ý tưởng, triển khai các nội dung và hoàn thiện bản thảo cuối của bài báo; tác giả Vũ Đình Trọng cùng triển khai các nội dung và đọc bản thảo; các tác giả Phạm Văn Việt, Nguyễn Anh Tuấn, Nguyễn Đình An thu thập số liệu, xử lý số liệu và triển khai thử nghiệm mô hình; tác giả Lê Thị Hương Giang nghiên cứu xây dựng thuật giải mô hình toán tối ưu.

\section{Tài liệu tham khảo}

C. Cullenbine, R. K. Wood và A. Newman, (2011). A sliding time window heuristic for open pit mine block sequencing, Optimization letters, 5 , tr. 365 - 377.

D. Joshi, S. Chatterjee và S. M. Equeenuddin, (2015). Limestone quarry production planning for consistent supply of raw materials to cement plant: A case study from Indian cement industry with a captive quarry, Journal of Mining Science, 51, tr. 980 - 992.

D. S. Hochbaum và A. Chen, (2000). Performance analysis and best implementations of old and new algorithms for the open - pit mining problem, Operations Research, 48, tr. 894 - 914.

D. S. Hochbaum, (2008). The pseudoflow algorithm: A new algorithm for the maximum flow problem, Operations research, 56, 992 1009.

H. Askari - Nasab, Y. Pourrahimian, E. Ben - Awuah và S. Kalantari, (2011). Mixed integer linear programming formulations for open pit production scheduling, Journal of Mining Science, 47, 338 trang.

Lerchs, H. và Grossman, F., (1965). Optimum design of open-pit mines, Transactions of CIM, LXVII.

IBM, ILOG CPLEX. 2009, Incline Village, NV.

I. Uublicatim Dciooer, (2003). Production scheduling at LKAB s Kiruna Mine using mixed 
- integer programming, Mining engineering, 35.

J. Whittle, (1988). Beyond optimization in open pit design, Canadian Conference on Computer Applications in the Mineral Industries, tr. 331 337.

K. Dagdelen và M. W. Asad, (2002). Optimum cement quarry scheduling algorithm, APCOM 2002, 30th International Symposium on the Application of Computers and Operations Research in the Mineral Industry, tr. 697 - 709.

K. Dagdelen, (2001). Open pit optimization strategies for improving economics of mining projects through mine planning, 17th International Mining Congress and Exhibition of Turkey, tr. 117 - 121.

L. Caccetta và S. P. Hill, (2003). An application of branch and cut to open pit mine scheduling, Journal of global optimization, 27, tr. 349 - 365.

MATLAB Software. MathWorks Inc. 9.3 (R2017b).

M. Gershon, (1987). Heuristic approaches for mine planning and production scheduling, International Journal of Mining and Geological Engineering, 5, tr. 1 - 13.

M. Godoy và R. Dimitrakopoulos, (2004) Managing risk and waste mining in long - term production scheduling of open - pit mines, $S M E$ transactions, 316 trang.

M. Pana và T. Carlson, (1966). Description of a computer technique used in mine planning of the Utah Mine of Kennnecott Copper Corp, 6th APCOM.

M.P. Gaupp, (2008). Methods for improving the tractability of the block sequencing problem for open pit mining, Colorado school of mines golden.

M. Tabesh và H. Askari - Nasab, (2011). Two stage clustering algorithm for block aggregation in open pit mines, Mining Technology, 120, tr. 158 - 169.

M. W. A. Asad, (2011). A heuristic approach to long - range production planning of cement quarry operations, Production Planning \& Control, 22, tr. $353-364$.

N. Boland, C. Fricke và G. Froyland, (2007). A strengthened formulation for the open pit mine production scheduling problem, Available at Optimization Online.

R. Chicoisne, D. Espinoza, M. Goycoolea, E. Moreno và E. Rubio, (2012). A new algorithm for the open - pit mine production scheduling problem, Operations Research, 60, tr. 517 - 528.

Rehman, S., MWA Asad và I Khattak, (2008). A Managerial Solution to Operational Control of the Raw Material Blending Problem in Cement Manufacturing Operations, Proceedings of the COMSATS International Conference on Management for Humanity and Prosperity, Lahore, Pakistan.

R. Goodfellow, (2014). Unifed Modelling and Simultaneous Optimization of Open Pit Mining Complexes with Supply Uncertainty. McGill University Libraries.

S. C. Johnson, (1967). Hierarchical clustering schemes, Psychometrika, 32, tr. 241 - 254.

S. Ramazan và K. Dagdelen, (1998). A new push back design algorithm in open pit mining, Proceedings of 17th MPES conference, Calgary, Canada, tr. 119 - 124.

S. Ramazan và R. Dimitrakopoulos, (2004). Traditional and new MIP models for production scheduling with in - situ grade variability, International Journal of Surface Mining, 18, tr. 85 - 98.

S. Ramazan, (2007). The new fundamental tree algorithm for production scheduling of open pit mines, European Journal of Operational Research, 177, tr. 1153 - 1166.

S. Srinivasan và D. Whittle (1996). Combined pit and blend optimization, Preprints - society of mining engineers of AIME.

S. U. Rehman và M. W. A. Asad, (2010). A mixed integer linear programming (MILP) model for short - range production scheduling of cement quarry operations, Asia - Pacific Journal of Operational Research, 27, 315 - 333.

T. B. Johnson, (1968). Optimum open pit mine production scheduling, California university berkeley operations research center.

Y. Zhao, (1992). A new optimal pit limit design algorithm, Proc. of the 23rd APCOM, 423 - 434. 